\title{
PEQUENO MAL E.PILEPTICO EM CRIANÇAS. CONSIDERAÇOES SOBRE O EFEITO DO TRIDIONE EM 4 CASOS
}

\section{ANTONIO B. LEFËVRE *}

O pequeno mal epiléptico é considerado, pela grande maioria dos autores, como manifestação epiléptica própria da infância e da adolescência. As estatísticas de Lennox e Gibbs confirmam, en grande parte, esta afirmação, pois $84 \%$ dos casos de pequeno mal por êles estudados ocorreram antes dos 20 anos de idade. O diagnóstico pelo EEG mostrou, igualmente, que $80 \%$ dos casos foram verificados em pacientes com menos de 20 anos de idade, chegando mesmo Lennox a afirmar que não se recorda de ter visto sequer um único caso de pequeno mal iniciado depois dos 20 anos.

As características comuns das diversas manifestações do pequeno mal são as seguintes, segundo Lennox ${ }^{\mathbf{1}}$ : grande freqüência das crises, brevidade dos ataques, início e terminação abruptos, manutenção da integridade mental, sensibilidade às variações do equilíbrio ácido-básico, bem como às concentrações do açúcar e do oxigênio no sangue, grande tendência à recuperação espontânea com a idade (exceto em certas formas acinéticas), falta de sinais de lesões cerebrais, resistência às drogas anticonvulsivas habituais.

Podemos observar diversos tipos de manifestações do pequeno mal, dentro destas características comuns. E' preciso que não se confunda o pequeno mal com uma pequena crise do grande mal, pois o p. m. tem características próprias, não significando esta denominação simples diferença de intensidade relativamente ao grande mal. As manifestações do p.m. podem ser classificadas em três grupos principais:

1. Pequeno mal pròpriamente dito ou picnocpilepsia - Consiste em breve lapso da consciência, com duração de 5 a 30 segundos. $O$ paciente em geral fica imóvel, mas pode apresentar rápidos e curtos abalos e tremores localizados nas pálpebras ou nas sobrancelhas. Excepcionalmente, é observado um "estado de pequeno mal" com crises ininterruptas e confusão mental concomitante. As crises são muito numerosas, porém o intervalo entre as crises sucessivas é caracterizado pela perfeita lucidez do paciente, não se observando estado de torpor em seguida às crises. Tal como nas demais formas de p.m., a picnoepilepsia se manifesta preponderantemente nas horas matinais, podendo as crises ser precipitadas pelas emoções fortes. Nos pacientes do sexo feminino nota-se um recrudescimento do número de crises durante os períodos de menstruação. As meninas são mais su-

Trabalho apresentado à Secção de Neuro-Psiquiatria da Associação Paulista de Medicina, em 5 outubro 1948 .

* Assistente de Clínica Neurológica na Fac. Med. Univ. São Paulo (Prof. A. Tolosa).

1. Lennox, W. - The petit mal epilepsies. Their treatment with Tridione. J.A.M.A., 129:1069.1073 (dezembro) 1945. 
jeitas do que os meninos. Podem ser observadas formas subclínicas, reveláveis apenas pelo EEG. A hiperventilação pulmonar funciona como elemento desencadeante, o que permite a obtenção de nítidos traçados ao EEG, na maioria dos casos.

2. Epilepsia mioclônica - Não confundir com a forma, muito grave, de Unverricht. Nestas formas de p.m. observam-se contrações simples ou choques dos músculos flexores, geralmente envolvendo um ou os dois membros, afetando, também, com freqüência, os músculos do tronco. Não há lapso da consciência como na forma anteriormente descrita. Assemelham-se muito aos choques que as pessoas normais apresentam no momento de conciliar o sono.

3. Epilepsia acinética (epilepsia estática de Ramsay Hunt) - Súbita perda do contrôle postural, podendo o paciente apresentar rápida queda. Sem qualquer aviso ou contração muscular, a criança sùbitamente cai. Geralmente, levanta-se ràpidamente, porém pode permanecer inconsciente ou com dificuldade para caminhar durante alguns minutos. Distinguem-se das crises catapléticas da narcolepsia, porque falta o componente emocional desencadeador e, também, porque se podem repetir mais de uma centena de vêzes ao dia. Algumas vêzes existe, na história pregressa, um passado sugestivo de encefalite ou trauma obstétrico acompanhado de asfixia neonatal. O EEG é um pouco mais confuso do que nas demais formas, porque pode apresentar diversas anormalidades.

A terapêutica do p.m. não estava acompanhando, até poucos anos atrás, os progressos daquela referente ao grande mal e aos eqüivalentes psicomotores. A única terapêutica que havia produzido resultados de certa forma compensadores era a dieta cetogênica: contudo, os resultados apresentados pelos diversos autores são muito variáveis, pois a dieta é muito difícil de ser mantida, a menos que os pacientes estejam em regime hospitalar. Além disso, há resultados bastante desanimadores com esta terapêutica em casos perfeitamente controlados. A difenilhidantoína, que parece produzir excelentes resultados no grande mal, não produz o menor resultado favorável no p.m., parecendo mesmo agravar as manifestações. Os melhores resultados obtidos até os últimos tempos eram registrados com o emprêgo da associação da benzedrina com os fenobarbitúricos. Com relação ao emprêgo isolado do ácido glutâmico, há poucas e contraditórias referências.

O Tridione $(3,5,5$ - trimetiloxazolidina 2,4 - diona $)$ foi primeiramente empregado como analgésico e, em seguida, como anticonvulsivo. Segundo Richards ${ }^{2}$, que estudou sua farmacologia, êste medicamento aumenta o limiar convulsógeno, tanto para as crises desencadearlas pelo cardiazol, como pelo eletrochoque. Perlstein ${ }^{3}$ empregou o Tridione em numerosas afecções do sistema nervoso. De suas observações, as que mais nos interessam no momento são aquelas relativas ao tratamento do p.m. idiopático, em que os resultados obtidos foram muito bons, com

2. Richards, R. K. - Tridione: a new experimental drug for treatment of convulsive and related disorders. Pharmacologic aspects. Arch. Neurol. a. Psychiat., 55:164 (fevereiro) 1946.

3. Pelstein, M. A. - Tridione: a new experimental drug for treatment of convulsive and related disorders. Clinical investigations. Arch. Neurol. a. Psychiat., 55:165 (fevereiro) 1946. 
melhora considerável em $5 / 6$ casos. Foram ainda obtidos resultados interessantes com êste medicamento en casos de paralisia cerebral infantil de forma atetóide ( 7 crianças observadas apresentaram sensíveis mellhoras), en distúrbios funcionais da conduta (4 crianças com sérios distúrbios da conduta apresentaram notável melhora). Em 2/4 casos de tétano infantil foi obtido bom resultado sôbre as convulsões. Nenhum resultado foi obtido com o Tridione nas encefalopatias infantis em que há comprometimento do tracto piramidal, bem como nos casos de coréia de Sydenham.

A experiência de Lennox com o Tridione no tratamento do pequeno mal evidenciou resultados verdadeiramente dramáticos, segundo sua própria expressão. De 40 pacientes com uma história típica de pequeno mal, $28 \%$ ficaram completamente livres das crises e $52 \%$ tiveram redução considerável das crises, entendendo-se por isto uma redução de $75 \%$ ou mais sôbre o número das crises; os restantes $20 \%$ melhoraram moderamente. Em 10 pacientes que tinham também crises de grande mal não houve qualquer benefício com relação a estas últimas, havendo mesmo certo agravamento, possivelmente por supressão dos anticonvulsivantes habituais. Houston Merritt ${ }^{4}$, com uma experiência bem menor do que a de Lennox, considera também o Tridione como o medicamento de escolha para o tratamento do pequeno mal. Estudou três pacientes com os quais obteve excelentes resultados, com cessação completa das crises enquanto sob a ação do medicamento.

Dosagem - O medicamento existe na praça sob forma de cápsulas gelatinosas, na dosagem de $0,3 \mathrm{grs}$. A dose individual pode variar muito de um paciente para outro, sendo recomendável tactear a sensibilidade individual. Em criança pequena, pode-se iniciar com meia cápsula nas 24 horas; em adulto, inicia-se com uma a uma e meia cápsula ao dia. As doses podem ser muito aumentadas, sem efeitos colaterais desagradáveis. Um dos pacientes de Merrit, com 10 anos de idade, fêz uso diário de 4 cápsulas de Tridione sem qualquer efeito desagradável.

Efeitos colaterais e contra-indicações - Não há distúrbios gástricos dignos de nota. Em grande número de pacientes adultos ou adolescentes foi observado deslumbramento visual; excepcionalmente, as crianças apresentaram êste sintoma. Deve-se notar que o deslumbramento desaparece completamnte com a supressão do medicamento. As experiências de Lennox, Merritt, Richards e Perlstein são unânimes na afirmação da pequena toxicidade do medicamento, que pode ser dado, mesmo a crianças, durante longo espaço de tempo. Nos 40 casos estudados por Lennox, apenas em dois houve sintomas tóxicos sérios, nenhum dêles mortal. Outros autores citam erupções cutâneas e náuseas como efeitos colaterais. Mackay e Gottstein 5 citam um caso fatal em paciente com 23 anos de icade com uma

4. Merritt, H. H. - Recent advances in treatment of epilepsy, with particular emphasis on use of Tridione. Arch. Neurol. a. Psychiat., 57:130-133 (janeiro) 1947.

5. Mackay, R. P. C Gottstein, W. K. - Aplastic anemia and agranulocytosis following Tridione (a fatal case). J.A.M.A., 132:13-16 (setembro) 1946.

6. Harrison, F. F. e Johnson, R. D. - Fatal aplastic anemia following use of Tridione and hydantoin. J.A.M.A., 132:11-13 (setembro) 1946. 
forma mixta de pequeno e grande mal; a paciente estava sendo submetida a tratamento pelo Tridione associado a fenobarbitúricos, quando apresentou um quadro de anemia aplástica com forte tendência para hemorragias; o mecanismo de ação nociva da droga não pôde ser apreciado. Outro caso fatal foi referido por Harrison e Johnson 6 . Existe apenas uma contra-indicação para o emprêgo do Tridione: êle deve ser evitado em pacientes com formas graves de anemia de qualquer tipo. Como cuidados especiais durante a administração do medicamento, devem ser feitos hemogramas cada 15 dias. As doses iniciais devem ser pequenas. O período das menstruações é particularmente favorável ao aparecimento das manifestaçc̃es de anemia, merecendo, portanto, cuidados especiais. $O$ medicamento não deve ser vendido sem prescrição médica, nem administrado sem contrôle médico. E' altamente recomendável o contrôle diário do número de crises com o fim de calcular e prescrever a dose suficiente e necessária.

\section{OBSERVAÇÖES}

CAso 1 - M.-H. S., 3 anos, branca, brasileira, examinada pela primeira vez em 19 de maio de 1948. Filha única de pais sadios. Antecedentes familiares sem importância. Nascida de parto trabalhoso, traumático, após gravidez fisiológica; foi usado fórcipe. Asfixia neonatal de duração não precisada, tendo sido empregadas manobras para reanimação. Passou bem até três semanas antes da primeira consulta. Desenvolvimento psicomotor dentro dos limites normais. Por esta época, sem qualquer razão aparente, começou a apresentar crises muito freqüentes e de curta duração, repetindo-se 20 a 30 vêzes nas 24 horas. Foi examinada por pediatra, que nada encontrou ao exame geral. Assistimos a uma das crises, ccorrida durante a consulta. A paciente estava sentada em um banquinho, quando, sùbitamente, girou a cabeça para a esquerda, começou a gemer $e$ os músculos posturais perderam o tono, caindo a cabeça em flexão. A paciente não chegou a cair no chão; não apresentou movimentos tônicos ou clônicos; não urinou, evacuou, babou ou gritou. A crise durou menos de 30 segundos. Logo em seguida obtivemos um esbôço de sinal de Babinski no pé esquerdo. os dois olhos apresentavam as pupilas em midríase. A mãe informou que as crises eram muito semelhantes a esta, chegando a criança a cair quando estava de pé. $O$ exame neurológico não mostrou qualquer anormalidade; não houve periodo de torpor em seguida à crise; Q. M. normal, de acôrdo com as tabelas de Gesel; Q. I. normal, pràticamente igual a 1 . Foram feitos exames de líqüido cefalorraquidiano radiografias do crânio e parasitológico ce fezes, que nada indicaram de anormal.

Iniciou o tratamento com $1 / 2$ cápsula de Tridione ao dia. Foi prescrita dieta cetogênica. Do relatório semanal da mãe anotamos o seguinte: durante a primeira semana de tratamento as crises se reduziram para 7 , em média, por dia; passou. então, a tomar $\mathrm{s} / 2$ cápsula 2 vêzes ao dia; durante a segunda semana teve, em 4 dias, 2 crises por dia, rãao tendo nenhuma crise nos outros três dias; na terceira semana, o número de crises se reduziu à metade, o mesmo se dando na quarta. A partir de então, durante um prazo de observação de três meses apresentơ apenas uma única crise. muito mais fraca do que as anteriores. Durante todo o tempo tomou apenas a medicação acima exposta. Continuou com a dieta cetogênica muito branda, não muito observada pela paciente. pois ela comia doces e balas com certa freqüência. Foi vista pela última vez em 20 de outubro; passava muito bem; havia engordado; apetite muito melhorado; bom ajustamento no lar.

Caso 2 - L. A. V. A., 1 ano, brasileiro, branco, observado desce 23 de junho de 1948. E' o segundo filho. O primeiro é normal. Pais sadios. Nascido de parto cirúrgico após gestação fisiológica. Perímetro cefálico de $36 \mathrm{cms}$. por ocasião do nascimento. Não houve asfixia neo-natal. Passou bem até os 6 meses, 
alimentado artificialmente. Por esta ocasião, teve um quadro febril, diagnosticado como rinofaringite pelo pediatra que o acompanha desde o nascimento; permaneceu com temperatura elevada durante três dias. Em seguida, foi notado estrabismo convergente. Foi feito um exame de líqüido cefalorraqueano, que nada revelou de anormal nesta ocasião. Um mês depois, começou a apresentar crises com as seguintes características: sùbitamente, ficava com os olhos parados, fixos, com expressão apática; estas crises eram muito rápidas, durando 10 a 15 segundos, repetindo-se mais de 40 vêzes por dia. Fêz numerosos tratamentos, sem qualquer resultado. Por ocasiãa da primeira consulta, o desenvolvimento psicomotor era normal e o exame neurológico inteiramente normal. O perímetro cefálico era de $49 \mathrm{cms}$. Assistimos a duas crises durante a consulta: o paciente estava de pé, seguro pela mãe, quando, sùbitamente, perdeu o tono de postura e caiu ao chão, com expressão apática, sem gritar, sem urinar ou babar, sem movimentos tônicos ou clónicos. A crise foi rapidíssima, pois já tinha cedido ao ser o paciente levantado do chão. O EEG mostrou disritmias típicas de pequeno mal.

O tratamento instituído foi o seguinte: Tridione, $1 / 2$ cápsula 2 vêzes ao dia; ácido glutâmico, um comprimido 3 vêzes ao dia; radioterapia superficial cerebral difusa. Voltơ à consulta depois de um mês. Do relatório da mãe anotamos o seguinte: nos primeiros 15 dias de tratamento, as crises se reduziram para uma média de 9 ao dia; na semana seguinte, baixaram para 4, em média, por dia; a partir do tèrmino da terceira semana, durante 85 dias de observação apresentou uma única crise durante um período de hipertermia por rinofaringite. Estamos informados que há 2 meses não apresenta nenhuma crise. Continua com a medicação até hoje. Novo EEG mostrou desaparecimento dos ritmos anormais.

Caso 3 - M. L. A., 5 anos e meio, branca, brasileira, observada desde outubro de 1947. E' a segunda filha. Tem um irmão sadio. Pais sadios. Não há antecedentes familiares dignos de nota. Nascida a têrmo, de parto normal após gestação fisiológica. Com um mês de idade apresentou-se febril, com temperatura muito elevada durante alguns dias; no curso dêste quadro febril apresentou uma convulsão localizada no hemicorpo direito, ficando, em seguida, com hemiplegia direita. Nessa ocasião, foi examinada por neurologista, tendo sido feito o diagnóstico de encefalite a vírus. Pouco tempo depois dêste acidente inicial, começou a apresentar crises de pequeno mal, assim descritas: sùbitamente, leva a mão an abdome, fica com a expressão parada, mortiça, abre os hraços, chora um pouco e, depcis, retorna ao normal. Com o desenvolvimento, as crises se alteraram um tanto: sùbitamente, começava a chorar com uma expressão de mal-estar no rosto, corria para o colo da mãe ou ficava parada no local por poucos segundos, retornando depois ao normal. Nunca teve crises de grande mal. O desenvolvimento motor, apesar do déficit da movimentação voluntária no hemicorpo direito, fêz-se sem retardos dignos de nota. A palavra e a linguagem se desenvolveram dentro dos limites da normalidade. Ao ser examinada por nós, apresentava seqüela de hemiplegia direita de tipo piramidal; andava com certa dificuldade, esboçando marcha ceifante; a paresia que apresenta é desproporcional, atinginco mais o membro superior do que o inferior $e$ a face; o membro superior direito apresenta-se com hipertonia em flexão; sinal de Babinski no pé direito; reflexos osteotendinosos vivos, um pouco mais à direita. não apresenta distúrbios da palavra ou da linguagem; astereognosia na mão direita; nível mental ao Binet-Terman (apenas as provas verbais) próximo à idade cronológica; $Q$. $I=0.9$. A paciente esteve sob os cuidacios de médico especialista desde o nascimento. Fêz três séries de radioterapia. Tomou pràticamente todos os anticonvulsivos de uso corrente. Os exames paraclínicos que pedimos na ocasião nada revelaram de anormal. Não foi feito o EEG, por falta de colaboração da paciente. Ao 
exame clínico foi notada presença de amígdalas hipertróficas. A paciente tem tendência a manifestações alérgicas do tipo da rinite espasmódica.

Começamos o tratamento recomendando, inicialmente, a dieta cetogênica, Gardenal 0,05 ao dia e ácido glutâmico (6 comprimidos ao dia). Por esta ocasião, a paciente estava tendo uma média de 4 a 5 crises por dia. As crises não se reduziram de número, embora a paciente ficasse um pouco mais calma. Depois de dois meses desta terapêutica, passamos a usar o Tridione na dose de $1 / 2$ cápsula cuas vêzes ao dia, juntamente com o ácido glutâmico e a dieta cetogênica, tendo sido suprimido o Gardenal. Do relatório feito pela mãe a partir desta época, assinalamos o seguinte: no primeiro mês de tratamento teve apenas 5 crises nos dias $5,16,18$ ( 2 vêzes) e 19 de janeiro, sendo que, nestes últimos dois dias, estava resfriada e com temperatura elevada. Desde o mês de fevereiro até o de outubro, o número de crises foi o seguinte $5-3-4-2-6$ (resfriado com hipertermia de $38^{\circ} \mathrm{C}$ ) $-2-4-10$ (oito das quais ocorridas durante três dias em que teve um resfriado muito forte, com grande elevação térmica). Em outubro foi amigdalectomizada. O estado geral melhorou muito. Atualmente, está muito mais calma e confiante, freqüentando escola com borm aproveitamento e boa adaptação. Tomou o medicamento durante todo o tempo sem qualquer manifestação tóxica.

Caso 4 - L. F. F., 2 anos, brasileiro, branco, observado desde dezembro de 1947. E' filho único. Não há casos de moléstias nervosas em parentes próximos. Parto normal após gestação fisiológica. Desde os 7 meses de idade vem apresentando crises, que podem ser assim descritas: o paciente sùbitamente abre os braços, fica parado no lugar. com uma expressão espantada, com se estivesse sem ar; não cai ao chão, não chora, não urina; ao fim de pouros segundos volta à situação normal. Depois de um pouco mais crescido, as crises provocam um estado de ansiedade: o paciente corre para os pais assim que a crise termina, chorando, aflito. O desenvolvimento psicomotor prccedeu-se com certo retardo. Começou a andar com 19 meses. Com 2 ancs, a palavra está muito pouco desenvolvida. De acôrdo com as tabelas de Gesel, podemos dizer que êste retardo é considerável apenas no setor da linguagem. Nos demais setôres, levando-se em conta que o paciente tem sido superprotegido em virtuce de sua doença, não há retardo digno de menção. $O$ exame do líquiido cefalorraqueano revelou hipercitose de 22,4 elementos por $\mathrm{mm}^{3}$, com $100 \%$ de linfócitos. Radiografia do pulmão normal. Reação de Mantoux negativa. Exame de fezes negativo.

Mandamos fazer, inicialmente, radioterapia superficial cerebral difusa e administrar 0,05 de Luminal por dia, juntamente com ácido glutâmico (4 comprimidos ao dia). As crises tornaram-se muito mais freqüentes com êste tratamento, chegando a ter $17 \mathrm{em}$ um só dia. No mès de maio passou a tomar Tridione ( $\mathrm{I} / 2$ cápsula por dia), juntamente com o ácido glutâmico. Um mês depois, as crises haviam diminuído para 3 ou 4 ao dia, sendo de intensidade muito fraca. Foi, então, duplicada a dose do medicamento. Durante os meses de julho a outubro, teve apenas uma única crise em um dia em que sofreu uma queda muito forte. Durante êste período passou 15 dias sem tomar o medicamento por ter havido falta do mesmo na praça. Não teve qualquer crise nos dias em que ficcu sem o medicamento.

\section{CONCLUSOFS}

Da exposição feita e dos resultados colhidos parece-nos ser permitido afirmar que o Tridione é, atualmente, o medicamento de eleição para o tratamento do pequeno mal. Sua ação é altamente eficiente, 
mesmo quando o medicamento é ministrado em doses relativamente baixas como as empregadas em nossos pacientes. Não observamos qualquer efeito colateral desagradável, mesmo nos casos em que o medicamento foi empregado por um tempo bastante longo. Sua tolerância é perfeita, mesmo para crianças na primeira infância.

\section{SUMMARY}

The author administered Tridione in four patients under five years of age with "petit mal" seizures. In all cases there was complete disappearance of the seizures eventhough small doses were used. In one case the EEG, taken after the Tridione treatment, did not show the previous "petit mal" pattern. In no case there were signs of intolerance. In conclusion the author thoroughly agree that Tridione is the drug of choice in "petit mal" seizures.

Alamcda Franca, 909 - S. Paulo 